\title{
Decelerated IT Innovation: Negotiating Global IT Innovation Initiatives in Local Settings
}

\author{
Johan Sandberg \\ Umeå University \\ jsberg@informatik.umu.se
}

\author{
Jonny Holmström \\ Umeå University \\ jhstrom@informatik.umu.se
}

\author{
Kalle Lyytinen \\ Case Western Reserve University \\ kalle@ case.edu
}

\begin{abstract}
:
We examine an attempt to implement a joint IT infrastructure between a large multi-national hightechnology manufacturing firm and a large mining firm. We identify several occasions where innovation failed and the manufacturing firm could not establish a new network of partnerships with their customers enabled by the introduced IT capabilities. Our study highlights a change in the forms of materiality within used control system technology - a shift from controlling isolated manufacturing devices into controlling networks of "smart" devices connected by Internet computing. While the new networked and ubiquitous computing infrastructure holds a potential for radical service innovation, this potential has not been fulfilled. One of the factors accounting for the failure is that the global IT innovation strategy was not well aligned to the local context and existing networks of actors. To explain this unfolding of events we coin the term "decelerated innovation".
\end{abstract}

\section{Introduction}

The pace of change in the Information Technology (IT) field has been rapid over the past decades resulting in a host of new technologies available to realize "sense and respond" capabilities towards firm's customer base. However, the increased complexity of these technologies due to their infrastructural nature and often inadequate implementation tactics have led to multiple failures [22]. This heightened complexity is generated by the fact that the new technological components - as infrastructure - need to be connected to the installed base, business processes, people, standards and operating knowledge. Yet, such technological components are often viewed by implementers solely as isolated technical artifacts, hiding their real design and implementation complexity.

Recently the introduction of such technologies has been increasingly studied using an innovation perspective [20]. In such a view, the introduction of IT components is approached as an innovation process consisting of multiple interdependent elements interconnected in a socio-technical network [5]. These studies have examined in particular the impacts of IT infrastructures on the firm's performance and innovation capability (see e.g $[5 ; 10]$ ), and the processes of digitization [31]. Here digital innovation is seen to offer new options and threats for firms. Embedding ICT capabilities may enable new business models [15], require new infrastructural strategies [28], enable non-hierachical organizing models [12] and promote open innovation [32]. At the same time digital innovation challenges firms' traditional desire to hierarchical control and functional orientation during the innovation [32]. In responding to this challenge, firms need to distribute control and integrate diverse pools of knowledge. This can be a challenge in a context where the dominant mode of product development has been shaped over long periods of incremental innovation with vertical control and functional lines [3]. To appreciate the importance of integrated IT infrastructures we therefore need to understand ways in which they both enable and inhibit innovation. Against this backdrop, this research addresses the following research question: How can industrial firms reconfigure traditional approaches to innovation to leverage new digital options as part of their innovations?

In this paper we examine in particular the tension between the local and global innovation during infrastructural innovation as firms seek reconfigure their traditional approaches to innovation. We probe, in particular, an attempt to implement a joint IT infrastructure between a large multi-national hightechnology manufacturing firm (ABB) and a large mining firm (LKAB). We identify several occasions where the planned innovation failed and the manufacturing firm could not establish a new network of partnerships with their customers enabled by the introduced IT capabilities. We trace changes carried out by the firms in their attempts to transform their business towards the service orientation and change their innovation processes. In particular we explore ServIS, a project where the IT innovation which 
initially failed in increasing service orientation. However, after some turmoil the project has continued albeit with a decelerated pace. We coin the term decelerated innovation to portray how and why complex networking technologies can lead to innovation outcomes, but at a decelerated pace, and failing to meet initial goals with the innovation outcomes due to socio-technical negotiation processes in the innovation project.

The remainder of this paper is structured as follows. It begins by reviewing the extant literature on IT innovation. Actor-network theory (ANT) is presented as our analytical lens. A case study conducted at $\mathrm{ABB} / \mathrm{LKAB}$ is presented, and finally, the implications of this work for research and practice are outlined.

\section{Literature review}

Although research on IT and organizational transformation has been pursued actively over the last two decades, results have not found causal connection between IT and organizational change. While in professional rhetoric IT remains firmly associated with the agenda of organizational transformation, the research literature suggests a more complicated pattern. Several critical reviews advocate that IT's organizational consequences form an emergent process rather than a deterministic outcome $[21 ; 26]$. In contrast to causal argument, emergent causality suggests no necessary causal relationship between IT and organizational change. Rather, IT and organization can be seen as aspects of a structure that is mutually implicated [25]. In our exploration of how interconnected technological, and social elements enable innovative use of IT we therefore build on existing research on socio-technical IT innovation in general, and actor-network theory in particular.

\subsection{IT Innovation}

A widely accepted definition of organizational innovation is that it involves adoption of an idea, material artefact, or behavior that is new to the organization adopting it [9]. While the innovation literature is diverse, two important streams can be distinguished: (1) theories of industrial innovation and (2) the diffusion of innovation literature. The first research stream deals with specific types of innovations: artefacts and ideas that are new to a particular industry. Industrial innovation research has examined characteristics of an industry, product, market, or organization, and has asked why and how ideas, organizing patterns, or artefacts that are novel for the industry emerge, and what their impacts are (e.g. [1]). The diffusion of innovation research stream, on the other hand, has focused on the ways in which innovations spreads over time and space. This research stream has focused on the innovation demand side, and primarily applied diffusion of innovation theory to discern patterns of diffusion (e.g. [27]).

Table 1. Subcategories of IT Innovation (Lyytinen \& Rose [20]

\begin{tabular}{|c|c|c|}
\hline $\begin{array}{l}\text { IT } \\
\text { Innovation } \\
\text { Sets }\end{array}$ & Description & Examples \\
\hline \multirow{3}{*}{$\begin{array}{l}\text { IT Base } \\
\text { (Base) }\end{array}$} & $\begin{array}{l}\text { Base Technology } \\
\text { Innovation (Base 1) }\end{array}$ & $\begin{array}{l}\text { DBMS, Client/Server } \\
\text { Computing; OODB }\end{array}$ \\
\hline & $\begin{array}{l}\text { Base Development } \\
\text { Capability Innovation } \\
\text { (Base 2) }\end{array}$ & $\begin{array}{l}\text { Software Patterns: } \\
\text { Software Component } \\
\text { Brokering, Quality } \\
\text { Assurance }\end{array}$ \\
\hline & $\begin{array}{lr}\text { B a se } & \text { Service } \\
\text { Capability } & \text { Innovation } \\
\text { (Base 3) } & \end{array}$ & $\begin{array}{l}\text { Point-and Click GUI, } \\
\text { Multimedia, QoS }\end{array}$ \\
\hline \multirow{2}{*}{$\begin{array}{l}\text { System } \\
\text { Development } \\
\text { (SD) }\end{array}$} & $\begin{array}{l}\text { Administrative Process } \\
\text { Innovation (SD 1) }\end{array}$ & $\begin{array}{l}\text { Maintenance } \\
\text { departmentalization, } \\
\text { CIO, open source } \\
\text { development }\end{array}$ \\
\hline & $\begin{array}{l}\text { Technical Process } \\
\text { Innovation (SD2) }\end{array}$ & $\begin{array}{l}\text { Systems programming, } \\
\text { data administration, } \\
\text { prototyping }\end{array}$ \\
\hline \multirow{4}{*}{$\begin{array}{l}\text { Services } \\
\text { (S) }\end{array}$} & $\begin{array}{l}\text { Administrative Process } \\
\text { Innovation (S1) }\end{array}$ & Accounting systems, EIS \\
\hline & $\begin{array}{l}\text { Technological Process } \\
\text { Innovation (S2) }\end{array}$ & $\begin{array}{l}\text { MRP, } \quad \text { computer } \\
\text { integrated manufacturing }\end{array}$ \\
\hline & $\begin{array}{l}\text { Technological Service } \\
\text { innovation (S3) }\end{array}$ & $\begin{array}{l}\text { Remote customer order } \\
\text { entry and follow-on } \\
\text { customer service systems }\end{array}$ \\
\hline & $\begin{array}{l}\text { Technological } \\
\text { Integration Innovation } \\
\text { (S4) }\end{array}$ & $\begin{array}{l}\text { Interorganizational } \\
\text { information systems, EDI }\end{array}$ \\
\hline
\end{tabular}

Lyytinen and Rose [20] distinguish further between three types of IT innovations and their interactions in a three-set model of IT innovation. The first type of IT innovation - IT base innovations - refers to innovation associated with computing capability. IT base innovations may include new software and hardware architectures and services. The second innovation type involves changes in system development processes. The third type of innovation consists of outcomes of development processes, services. For both of the two later IT innovation types, changes in computing capability are typically critical enablers. The three sets 
of innovations are mutually dependent - innovation in one type may spawn innovations in others [17]. Table 1 shows sub categories of the three innovation types and provides some examples. In order to better explore the ways in which social and technical elements are intertwined and how these elements are co-producing the heterogeneous assemblages that is a precondition for IT innovation on the social and technical levels, we will make use of ANT as analytical lens.

\subsection{ANT}

While many approaches to IS research treat the social and the technical in entirely different ways, ANT proposes a socio-technical account in which neither social nor technical positions are privileged over the other. ANT deals with the social-technical divide by denying that purely technical or purely social relations are possible. Instead it considers the world to be full of hybrid socio-technical entities [17] containing both human and non-human elements. ANT developed around problems associated with attempts to better understand socio-technical assemblages like electric cars [7], a supersonic aircraft [18], and a new railway system in Paris [17]. According to ANT, human and non-human actors are linked together in a web of relationships referred to as an actor network. Within an actor network, the interests of various actors are translated and inscribed into technical and social arrangements. Through the processes of translation and inscription, actors' heterogeneous interests become aligned with each other and embedded into technologies that stabilize the actor network, at least temporarily $[2 ; 8]$. Once stabilized, an actor network may become seemingly irreversible and thus resistant to further translation [8]. With its focus on actions within an actor network, ANT stands in sharp contrast to theories of technology diffusion [14]. Diffusion theory describes innovation as a process in which definable factors affect the decision to adopt or not to adopt a particular technological artefact. ANT regards the technological artefact as being moved and changed by social actors who are engaged with it. Actors not only reshape technologies but actors themselves change as the changing artefact spreads through a social network. Thus, one of ANT's central principles is that nonhuman technologies also become actors in actor networks. As programs of actions are inscribed into technology, it becomes an actor that imposes its inscribed program of action on its users [13]. Inscriptions may vary in strength. Strong inscriptions leave little room for interpretative flexibility, whereas weak inscriptions leave some room for interpretation
[23]. Translation refers to the process in which actors reinterpret and appropriate each other's interest to their own. This process of translation embeds technology into the context of use, producing stability and social order $[3 ; 7 ; 19 ; 22]$. The main advice on method suggested by proponents of ANT is to "follow the actors" $[7 ; 8 ; 17]$ and to let them set the framework and limits of the study themselves. In what follows we concentrate on issues of network formation and expansion, investigating human and non-human actors, the alliances and networks they build up, and how these networks expand or, as the case was in the present study, failed to expand.

\section{Research Site and Methods}

Our research study was inductive and focused on exploring ServIS, a project aimed at implementing an IS regarding installed base at customer sites. By examining the technological development in the area of control systems, a critical technology in larger process industries, we asked how industrial firms can reconfigure traditional approaches to innovation to leverage new digital options as part of their innovations.

\subsection{Research Site}

The research presented in this case explores innovation processes and their effects on the IT supplier ABB and one of their customers; LKAB, Sweden's leading producer of upgraded iron ore products. LKAB has about 3800 employees, a yearly turnover of approximately 16 billion SEK and a production of over 20 million tonnes annually. ABB is one of the world's leading companies in power and automation technologies that operates in around 100 countries through their 115000 employees and holds a world leading position in the market of distributed control systems. Our focus is on the Swedish automation unit and the ServIS project, a project focused on a decision support system that contains information about installed $\mathrm{ABB}$ products at customer sites, because of this we considered data from customer to be important. LKAB being one of the bigger customers for $\mathrm{ABB}$ in the region with a business dependent on automation and thereby highly affected by this development in combination with supplying access to key informants appeared as a suitable study subject. 
Production processes in the context of the mining industry is very much automated and to a high degree steered by control systems. LKAB is heavily dependent on reliability of their systems since production stops are extremely expensive, and thus the performance of their IT supplier (in this case ABB) becomes an issue of strategic importance.

\subsection{Method}

A single case study was chosen for two reasons: (a) The in-house developed IS is company specific which suggests uniqueness [30 p. 40] and (b) our purpose was to provide a better understanding of changes in one setting rather than descriptive knowledge [24 p. 9].

The data in our study was collected through three different types of methods, semi-structured recorded interviews, follow up conversations and documents. Interviews were conducted with individuals holding broad varieties of professional roles such as project manager, key account manager, service manager and staff, IT manager and process engineers. The logic being that the professional role of informants in a substantial way would affect how events were perceived and that a relevant range of informants would provide a broader picture of events. In all seven persons were interviewed during approximately one hour and afterwards all audio recordings were transcribed. In a second confirmatory phase one key informant was interviewed on three occasions, these interviews were not audio recorded. In the data collection we focused on three areas: (1) changes in control system structure, (2) changes in the relationship between $\mathrm{ABB}$ and $\mathrm{LKAB}$ (such as business structure and services) and (3) ServIS and information processing regarding the installed base. In addition to data collected from the interviews $\mathrm{ABB}$ provided access to ServIS documentation of areas such as requirements specification and project development. These documents allowed greater insight into issues such as motives behind system development, intended users and architecture.

Analysis of qualitative data is an iterative and ongoing process that starts already during data collection. During the interviews the relationship between $\mathrm{ABB}$ and $\mathrm{LKAB}$ (2) was indeed a topic that informants acknowledged to be important but they also highlighted the impact of how other actors (third party suppliers) influenced this relationship. Another issue highlighted by informants was how the ServIS project was perceived at different hierarchical levels in ABB. When analyzing documents and the transcribed material the importance of these networks of actors led us to propose ANT as a useful lens for the case.

\section{Findings}

In what follows we describe the ways in which $A B B$ sought to diffuse their digital option ServIS throughout a network of heterogeneous actors. In particular we describe how the control systems market has evolved and how these changes constitute sources of an increased need of information about existing infrastructure components at various sites. We highlight a change in the forms of materiality within used control system technology. In particular we highlight a shift from controlling isolated manufacturing devices into controlling networks of "smart" devices connected by Internet computing. While the new networked and ubiquitous computing infrastructure holds a potential for radical service innovation, our finings show how potential has not been fulfilled.

\subsection{IT Base Innovation of Control Systems}

The first generation of control systems worked in an isolated setting, the systems were connected to specific parts of production that it steered but was otherwise detached from ambient systems and equipment. The architecture of control systems has however changed into network structures (Base 1 innovation). Functionality such as video surveillance of key parts/processes, improved production planning and integration of data are some of the advantages that can be drawn from these second-generation control systems. However updated software and knowledge about current versions has also become key factors in ensuring "up time" and production capability for firms hosting second-generation control systems.

In this second generation of production systems many individual components carry versatile computational capability implying that firmware needs to be taken into account. Increased integration of components with data processing holds potential large benefits, but also increases complexity in design and maintenance of systems. A project and service manager working with both new projects and service of existing sites summarizes the implications well:

When everything is integrated it's all connected, it becomes a bit like a puzzle, it's another way of thinking, a bit more complex but at the same time when it's done it's often better for the customer. They get a more integrated system but building it can be a bit more troublesome. An ABB unit can design the base, my division goes there and designs something and then another one, maybe not from ABB, another company, designs something that needs to communicate with our 
system. At the same time the customer has got their own application that also needs to communicate, data is to be sent and buss connections to be made.[...] Every little thing with a plug has got some kind of intelligence, it is firmware in every little piece with a plug. Project and service manager, ABB

Before the introduction of second-generation control systems software maintenance was almost a non-existing question. Instead, maintenance was mostly focused on mechanical parts and hardware. The system development occurred in a slow pace and the vast majority of changes were made locally due to demands from end-users. The use of third party suppliers and integration into larger networks implies new demands on maintenance work. A process engineer at LKAB describes the changes that are occurring in his work:

It [the system] is going to demand much more maintenance, earlier on, with the old systems, we just did some maintenance on the control systems when our customers, if you can call them that, the production sites wanted changes in the programs. Well there were some upgrades of the operator stations but that was very rare. Much of our work now will be to upgrade and keep after all hardware and software, not really the control systems but rather everything that is needed to keep the systems running. Process engineer, LKAB

Increased connectivity also implies increased interdependencies, changes in one part of the network affects, and is affected, by surrounding technology. Strengthening links between nodes lead to an increased need of knowledge about the installed base.

\subsection{System Development Innovation Expands the Network}

Traditionally most automation equipment in process industries were developed and produced in-house. This enabled suppliers such as ABB to obtain a large degree of control over the life cycle of products and associated software upgrades. Lately ABB has however started to incorporate external actors into their supply chain and system development. Using Lyytinen \& Rose's [20] taxonomy in table 1 we classify this as "Administrative Process Innovation" (SD 1).

ABB's main hardware supplier in regards to control systems is Hewlett Packard (HP) while Microsoft products are used as the software platform. This arrangement with increased reliance on third partysuppliers regarding modules of the control systems has led to fundamental changes, not only internally but also for the customers and the business structure. While the expected life span of the first generation of control systems without larger changes in the software was a significant number of years (ten to fifteen) infrastructural components which we refer to as the second generation of control systems has a pronounced shortened life span and is also in need of a continuous maintenance. Increased use of products from external suppliers implies that production systems development to a higher degree becomes influenced by progresses in the ambient IT environment. Companies such as Microsoft and HP are acting on highly competitive markets where constant technological innovation is necessary to survive. This rapid and continual innovation results in a steady stream of new products with better performance, making the existing ones obsolete. Innovation in these modules of control systems is however obviously aimed at a large number of heterogeneous customers than the specific needs of ABB customers in the control systems market. An $\mathrm{ABB}$ project manager describes these changes:

When shifting from making all products and systems ourselves to using Windows both $A B B$ and our customers has ended up in a situation where we do not control the development of IT products. We are purchasing hardware from third-part suppliers and they have got their own life cycle on products. [...] furthermore with Windows, as an example I use to talk about home PC's where you have got updates and patches that comes quite frequently, the situation is the same with our systems. Project manager, ABB

Dependency of external supplier's life cycle has created new challenges regarding both maintenance and spare parts and, as pointed out by the project manager, also regarding software. Being part of this innovation system conveys advantages; the second generation systems come with new opportunities regarding process automation. However, even though new functionality is provided customers do not only perceive the change as positive:

Process control systems, they were developed inhouse by different system suppliers, more or less everything was develop by the suppliers themselves [...]. Now we are using Windows as base, servers and... and we all know what is happening in the PC world, everything just spins faster and faster. New operating systems and new versions and this development will surely, well we will be affected by it as well. You used to be able to use the same system for ten to fifteen years, it won't exist in the future, we will have to upgrade more often, also the control systems unfortunately. IT manager, LKAB

What has happened can be described as a transformation from a rather sealed system environment to a multi-actor innovation network. Using Windows as a platform for control systems allows $\mathrm{ABB}$ to focus their product development on the 
actual control systems. Translation to the installed base and end user need however to a higher degree has to take place at a local level of the network. ABB and customers not only adopts and changes technology developed by other actors, but is also affected by innovation from them. Using externally developed products and connecting earlier detached systems and components have had profound effects on both business structure and information need.

\subsection{From Product Supplier to Technology Mediator}

ABB is a company with strong engineering traditions and a focus on developing high tech products. However, using third party suppliers in the case of control systems has changed the company's role. ABB has refined their automation business through a transition from a product portfolio containing all components of control systems to focusing on core activities of process automation.

When using third party suppliers ABB's development activities become directed towards adaptation of external innovation. In combination with increased system complexity service is increasingly becoming a major part of their business. One example of these business services is how they have taken over the handling of some of LKAB's spare parts. ABB takes responsibility for keeping spare parts in stock and except for a service fee LKAB does not pay for products until they leave the storage room. This is made possible through technological service innovation (S3 in table 1) in the form of an IS keeping track of products in storage and time of pick-up. As a response to the changes in software handling $\mathrm{ABB}$ is also offering their customers subscription on software updates. If the customer has got this subscription they receive e-mails regarding software patches and updates and access to validated solutions. Due to lack of updated and integrated information the communication however either takes place on a non-customized or a manual level. Another example of increased business service need related to maintenance is that $\mathrm{ABB}$ is inspecting LKAB's system every six-month, controlling the state of for example hard drives. However, service innovation has not had the same impact as IT base and system development innovation, one reason being strong organizational boundaries and the risk averse context.

\subsection{Increasing Knowledge About the Installed Base - The ServIS Project}

In $2006 \mathrm{ABB}$ launched the ServIS project with the purpose of increasing knowledge about the installed base at customer sites. Engineering and commissioning, manufacturing, sales and service were some of the units that were seen as potential users

Table 2. "ServIS Critical events"

\begin{tabular}{|c|c|c|c|}
\hline Timeframe & Situation that gives rise to decision & Decision & Consequences \\
\hline $2005-2006$ & $\begin{array}{l}\text { Growing recognition at } \mathrm{ABB} \text { for need of } \\
\text { knowledge about installed base at customer } \\
\text { sites, main reasons being desire to increase } \\
\text { sales and improve product life cycle } \\
\text { management. Different units (both functional } \\
\text { and geographical) hold local databases or } \\
\text { documents regarding installed base at } \\
\text { customer sites, there is however no firm-wide } \\
\text { access to this data. }\end{array}$ & $\begin{array}{l}\text { Create inter-organizational IS } \\
\text { (ServIS). }\end{array}$ & $\begin{array}{l}\text { ServIS project launched, the goal is } \\
\text { a highly integrated IS in order to } \\
\text { strengthen network links, create } \\
\text { better access to dispersed data, and } \\
\text { to align innovation strategy to IT } \\
\text { base innovations from third party } \\
\text { suppliers. The global IT innovation } \\
\text { strategy is thus translated to local } \\
\text { contexts. }\end{array}$ \\
\hline Fall 2007 & $\begin{array}{l}\text { Implementation strategy suffers from flaws } \\
\text { associated with its top-down approach with: } \\
\text { inconclusive understanding of local context; } \\
\text { insufficient resource allocation for migrating } \\
\text { and filtering existing data; conflicting } \\
\text { demands on departments and individuals } \\
\text { (billing customers vs. entering data); IS } \\
\text { development team's focus on integration with } \\
\text { existing systems (e.g. SAP) instead of "local } \\
\text { user" perspective; ServIS is in practice largely } \\
\text { ignored. }\end{array}$ & $\begin{array}{l}\text { Project management puts pressure on } \\
\text { departments to increase adoption. } \\
\text { Manager of Swedish service unit } \\
\text { emphasizes need of filling system } \\
\text { with data. }\end{array}$ & $\begin{array}{l}\text { ServIS contains non-complete, } \\
\text { redundant and non-quality assured } \\
\text { data, one reason being failure to } \\
\text { translate IS to context dependent } \\
\text { needs. Local understanding of } \\
\text { ServIS gradually shifts from a } \\
\text { promising tool for strengthening } \\
\text { inter-organizational links into non- } \\
\text { reliable solution. }\end{array}$ \\
\hline 2008 & $\begin{array}{l}\text { System is not used (at least not in Sweden) or } \\
\text { maintained. }\end{array}$ & $\begin{array}{l}\text { Management of Swedish part of the } \\
\text { project is handed over to group in } \\
\text { Zurich. }\end{array}$ & $\begin{array}{l}\text { Both management and use of } \\
\text { ServIS is separated from local to } \\
\text { global level. Innovation processes } \\
\text { decelerated. }\end{array}$ \\
\hline
\end{tabular}


benefitting from this IT service innovation. While not specifically intended for solving challenges related to innovation affecting control systems, ServIS seemed promising in regard to these in the sense that information about installed base is a key aspect for providing quality products and services. To this end the project is a failure, at least in relation to solving the lack of information in the Swedish automation unit. In this section we examine critical events leading to this failure.

ServIS is supposed to keep track of which products and versions that are in use at different customer sites. The idea was to incorporate data from different sources not only about the installed base (both ABB and third party products/systems) but also existing service contracts and performed maintenance. Much of this information already exists but is locally dispersed at different geographical and functional units and is not easily accessible. In the requirements specification the vision of the system is expressed: "The goal of the ServIS project is a single information systems, which provides detailed and up-to-date information about the installed base." Through information needed by the different units ABB hoped to improve aspects such as product life cycle handling, project management and service quality. ServIS is built with a client/server architecture with a relational database in the center. The vision was to integrate ServIS with other ABB information tools related to e.g. handling spare parts and extraction of data from other applications such as ERP systems and Excel files. In order to secure local acceptance the ambition was that it should not be necessary to enter the same information twice due to incompatible systems. Another important data source was thought to be manual information entered through web services by $\mathrm{ABB}$ personnel in connection with customer interaction.

The first step of implementation in the Swedish automation service unit was to manually enter existing data into ServIS. This was however not given high priority in the sense that personnel resources were not sufficiently assigned. According to the person in charge this was seen as a part-time job without sufficient acknowledgement while personnel in the unit at the same time largely are being measured on the amount of time that they spend working directly with customers. When data was not entered fast enough global project management put pressure on units to increase the pace. As a result one of the variables that became a measurement of project success was the amount of data that units entered into the system. In the Swedish automation unit a decision was made to enter existing data into the system without quality assuring it first. The logic behind this decision was that once data was entered the system would be used, users would remove incorrect and redundant data. Another problem was updates, since production stops are extremely expensive in many process industries systems security is given top priority and one effect is that production to a large degree are being kept isolated from external networks. Since much of the maintenance and acute replacements of products at sites are being carried out by customer's own personnel, ensuring updates of data was seen as a key challenge by members of the Swedish service unit:

ServIS needs to be automatically updated. What [the local ServIS project manager] will do now is to feed a lot of data into the system. In half a year, well then we do not know what the truth is if ServIS does not become so intelligent that it can connect to networks at customer sites and that our products shows that these cards are connected to the equipment at the site. Then you can search in ServIS and see, have they got any cards with this product revision and get an answer, yes, in these sites. Then we have a fantastic product, on the other hand if the data that is entered into the system is supposed to be updated manually, then the result will be ok, can we trust this? Project manager, $\mathrm{ABB}$

Users in the Swedish automation unit thus identified technological integration as a key for success. As mentioned above, connecting customers control systems directly to an ABB IS could be a sensitive issue, however other viable solutions where at hand. The control system 800XA offers the opportunity to export data. ABB service personnel could therefore collect this data at customer sites and then upload it to ServIS. However in order to import this data into ServIS some integration issues needed to be resolved. This was also conveyed to project management but on a global level integration with other systems such as SAP was given higher priority.

So far ServIS is not being used to any substantial degree by the Swedish unit, instead responsibility for project implementation has been moved to a group based in Zurich, Switzerland. Table 2 illustrates the dynamics of the forces that shaped the implementation process of ServIS in interaction with the local context. A global project management initially drove the process and their interests were expressed through a sequence of events that, over time, were changed through the interaction with the local context.

The global project management was pushing ServIS into existing network configurations with little understanding of how it would affect local practices. This severely hampered the expansion and ultimate success of the project. Through the events by which the initial ideas were changed, and through the interaction with the local context, the innovation process decelerated. 


\section{Discussion}

Our study sought to address the research question: How can industrial firms reconfigure traditional approaches to innovation to leverage new digital options as part of their innovations? In order to answer this question we coin the term decelerated innovation to describe how large-scale infrastructural projects fail to diffuse within and between organizations as the pace of innovation slows down and changes direction. Decelerated innovation portrays how and why complex networking technologies can lead to innovation outcomes, but at a decelerated pace, and failing to meet initial goals with the innovation outcomes due to sociotechnical negotiation processes in the innovation project. Existing research provides us with many examples of how projects of infrastructural character decelerate and thus drop pace as well as direction compared to initial ideas [e.g. 17: 22]. We have used ANT to analyze the organizational consequences of a particular application of information technology ServIS. We traced the origins of the ServIS project to economic pressures associated with maintenance work as well as after sales markets. Because ServIS afforded more detailed examinations of machine performances, it promised to increase the accountability of maintenance managers to base decisions about maintenance on rational criteria. Via translation, the interests of the initiators (ABB) were supposed to become the interests of a wider network of actors. This process failed. However, the ways in which the ServIS project failed is different from the types of failures described in the mainstream IS failure studies [11]. We coin the term decelerated innovation to focus on how and why complex networking technologies can and will lead to innovation. Looking at the types of IT innovation sets presented by Lyytinen \& Rose [20] it can be said that the ServIS project evolved in a fashion that translated only parts of these sets. The term decelerated innovation thus refer to the ways in which innovation takes part, but events in the innovation project influence the project so that deceleration of innovation occur. Project goals were met albeit in a decelerated way.

We also show how an actor-network approach to researching the IT infrastructure details the construction of networks and alliances to support and embed the changes envisioned by ABB. However, it is often the case that a firm, or a network of firms considering some technological innovation is interested in only some aspects of this innovation and not others [e.g. 14]. In actor-network terms a firm needs to translate [7] this piece of technology into a form where it can be adopted and holds a potential for innovative effects. As the project failed, and the industrial firm LKAB proved to be incapable to build value from the digital options, new knowledge about digital options and how to diffuse them within and between organizations are vital for industrial firms that seek to redefine their current innovation processes.

Our findings are significant in a number of distinctive ways. First, our study highlights different forms of materiality in control system technology i.e. a shift from isolated artefacts into Internet computing, e.g. artefacts with associated functionality and interdependencies. Considering the context of implementation (highly risk averse settings) this shift accentuates needs of information services related to the installed base. The processes of digitization were considered a risk at $\mathrm{LKAB}$, an attitude that severely contributed to the deceleration of innovation. Our results are thus underscoring the importance of the materiality e.g. the ways in which the specific characteristics of IT (in the form and shape of second generation control systems) had profound effects on their surroundings.

Second, innovation taking place in the IT base and system development administrative process has not been accompanied by innovation in services to any substantial degree. This also contributed to the decelerated pace of innovation. While the network architecture and ubiquitous computing infrastructure in the IT base holds a potential for a radical service innovation, this potential is yet to be fulfilled. ServIS failed to become the interorganizational system needed to provide information about the installed base. One of the explaining factors being how the global strategy was not aligned to the local context and the existing networks of actors. Table 3 presents our understanding of the innovation taking place in the network of actors related to control systems development and use.

Table 3. Subcategories of IT Innovation in the ServIS Context

\begin{tabular}{|l|l|}
\hline IT Innovation Sets & Innovation in process automation \\
\hline $\begin{array}{l}\text { IT Base } \\
\text { (Base) }\end{array}$ & $\begin{array}{l}\text { Network architecture, ubiquitous } \\
\text { computing (Base 1) }\end{array}$ \\
\hline $\begin{array}{l}\text { System Development } \\
\text { (SD) }\end{array}$ & Multi-actor R \& D process (SD 1) \\
\hline Services (S) & $\begin{array}{l}\text { - Minor innovation did take place e.g. } \\
\text { customer entry of spare parts pick up (S3) } \\
\text { and basic form of interorganizational IS } \\
\text { (S4) } \\
\text { - ServIS failed attempt, Technological } \\
\text { Integration Innovation did not take place } \\
\text { to a sufficient degree }\end{array}$ \\
\hline
\end{tabular}

Third, any expansion of the actor network presupposes a decreased control of technological 
development from ABB's perspective as third party suppliers aim their attention to a market that is opened up if only ABB's domination is delimited. To this end ABB faces the challenge of supplying their customers with validated and reliable products in a pace largely set by external actors. Moreover the pressure on customers to update their systems becomes severe under such conditions. Therein lies the catch 22: In order to provide service innovation and reliable products, the secondgeneration control systems with its network architecture and ubiquitous computing infrastructure, along with knowledge about the ever-changing installed base, is a necessity for ABB. But in order to accomplish preconditions for innovation, $\mathrm{ABB}$ needs to open up the marketplace for a heterogeneous set of actors, allowing for more sources for innovation than their own R\&D division. Reaching a new level of service innovation thus presupposes more actors and thus a decrease of control from ABB's perspective. The catch 22 situation contributed to a situation where the innovation decelerated, if not came to a stand still. Before this catch 22 is resolved any expansion of the actor-network is unlikely. In the ServIS project, the failure to expand the actor-network in such a direction lead to a deceleration of the innovation processes, looking at the project in terms "saving what could be saved" thus leading ABB to effectively deviate from the initial plans and leave such levels of innovation for future wakes of innovation. A second reason for decelerating innovation from ABB's perspective was found in LKAB's inability to comprehend the actual ambitions $\mathrm{ABB}$ held regarding service innovation.

\section{Conclusions}

IT applications have become pervasive in traditional industry settings, where they are often viewed as means to create and sustain effectiveness by enabling radical organizational transformations. Given the diverse empirical findings regarding IT's organization consequences - in industrial settings and elsewhere - contemporary theories have moved away from simple explanations of IT's role and rely increasingly on analyses of emergent social processes. In recognition of these trends, we used ANT to examine IT innovation in the mining industry. The ServIS project evolved in a fashion that translated only parts of the IT innovation sets presented by Lyytinen and Rose [20]. The term decelerated innovation thus refer to the ways in which innovation takes part, but socio-technical negotiation processes in the innovation project influence the project so that deceleration of innovation occur. Project goals were met albeit in a decelerated way.
Looking at the way in which the ServIS project unfolded it failed at an early stage after which the project management had to decelerate innovation in order to "save what could be saved" of the project. The initial global ideas had very little local support and the local project management was faced with a situation where the inscribed interests behind the IT innovation had to be re-negotiated. Divergent understanding and motives among actors (global/local, units, firms) for enacting the technology led to a situation where the project dropped pace and eventually came to a halt at the local level. We coin the term "decelerated innovation" to better focus on how the technology failed to diffuse and evolve in the network. Reducing strengths of inscriptions and developing innovation strategies based on a heterogeneous set of actors are two viable approaches for avoiding this state of decelerated innovation.

As an interpretive case study of a single organizational setting, our research does not strive for general explanations of organizational transformation [16]. Indeed, because the consequences of all IT applications are dependent on the social contexts in which they are enacted [25], we should expect a variety of outcomes even from the same IT application [26]. Our contribution, rather, is a demonstration of the expansion of actor networks, paying particural attention to the role played by IT within the network. To this end we have examined the process of change by conceiving of change as a series of negotiations that engage both human and nonhuman actors and extend into the future as negotiations continue.

\section{References}

[1] Abernathy, W., and Clark, K. Innovation: "Mapping the Winds of Creative Destruction", Research Policy (14:1), 1985. pp. 3-22.

[2] Akrich, M. "The de-scription of technical objects" Shaping technology/Building society, ed. W. E. Bijker and J. Law, MA: MIT Press ,Cambridge, 1992, pp. 205-224.

[3]Anderson, P., L.M. Tushman. "Technological Discontinuities and Dominant Designs: A Cyclical Model of Technological Change”. Administrative Science Quarterly, 34(4), 1990., pp. 604-633.

[4] Berg, M. and Timmermans, S., "Orders and Their Others: On the Constitution of Universalities in Medical Work." Configurations, vol. 8, 2000, pp. 31-61.

[5] Boland Jr,. R.J.,, Lyytinen, K. and Yoo, Y. "Wakes of Innovation in Project Networks: The Case of Digital 3-D Representations in Architecture, Engineering, and Construction", Organization Science, Vol. 18, No. 4, JulyAugust 2007, pp. 631-647 
[6] Börjesson, A and Mathiassen, L., "Improving Software Organizations: The Agility Challenge" Information, Technology \& People, Vol. 18, No. 4, 2005, pp. 359-382.

[7]Callon, M. "Some Elements of a Sociology of Translation: Domestication of the Scallops and Fishermen of St Brieuc Bay," in Power, Action and Belief: A Sociology of Knowledge?, J. Law (Ed.), London: Routledge and Kegan Paul, 1986, pp. 196-233.

[8] Callon . "Techno-economic networks and irreversible networks" in "A Sociology of monsters: essays on power, technology, and domination" (Ed..) J. Law, Routledge, 1991

[9] Daft, R. L., "A Dual-Core Model of Organizational Innovation", The Academy of Management Journal, Vol. 21, No. 2 (Jun., 1978), pp. 193-210

[10] Ellingsen. G. and Monteiro, E. "The organising vision of integrated health information systems", Health Informatics Journal, 14(3), 2008, pp. 223-236

[11]Ewusi-Mensah, K. 1997. Critical issues in abandoned information systems development projects. Commun. ACM 40, 9 (Sep. 1997), 74-80.

[12] Holmström, J., and Boudreau, M-C. "Communicating and coordinating: Occasions for information technology in loosely coupled organizations." Information Resources Management Journal, 19(4), 2006, pp. 23-38.

[13] Holmström, J., and Robey, D. "Understanding IT's organizational consequences: An actor network theory approach. pp. 165-187. In Czarniawska, B. and Hernes, T. (eds.) Actor-Network Theory and Organizing. Stockholm: Liber. 2005.

[14] Holmström, J., and Stalder, F "Drifting technologies and multi-purpose network: the case of the Swedish cashcard." Information and Organization, 11, 2001, pp. 187-206.

[15]Jonsson, K., Westergren, U. and Holmström, J. "Technologies for value creation: an exploration of remote diagnostics systems in the manufacturing industry". Information Systems Journal, 2008, Vol. 18, 3, pp. 227 - 245

[16] Klein, H. K., and Myers, M. D. "A set of principles for conducting and evaluating interpretive field studies in information systems", MIS Quarterly 23(1), 1999, pp. 67-94.

[17] Latour, B., "Aramis or the love of technology", Cambridge, Mass.., Harvard Univ. Press, 1996.

[18]Law, J. and Callon, M. "Engineering and Sociology in a Military Aircraft Project: A Network Analysis of Technological Change". Social Problems, Vol. 35, No. 3, Special Issue: The Sociology of Science and Technology (Jun., 1988), pp. 284-297
[19] Law, J., and Singleton, V. Object Lessons, Lancaster, UK: The Centre for Science Studies, Lancaster University, 1987.

[20] Lyytinen, K. and Rose, G.M. "The Disruptive Nature of Information Technology Innovations: The Case of Internet Computing in Systems Development Organizations", MIS Quarterly, Vol. 27, No. 4 Dec., 2003, pp. 557-596

[21] Markus, M.L. and Robey, D. Information Technology and Organizational Change: Causal Structure in Theory and Research, Management Science, Vol. 34, No. 5, May, 1988, pp. 583-598.

[22] Mähring, M., Holmström, J., Keil, M., and Montealegre, R. "Trojan Actor-Networks and Swift Translation: Bringing Actor-Network Theory to IT Project Escalation Studies," Information Technology and People (17:2), 2004, pp. 210238.

[23] Monteiro, E. "Actor-Network Theory," in From Control to Drift: The Dynamics of Corporate Information Infrastructure, C. U. Ciborra, K. Braa, A. Cordella, B. Dahlbom, A. Failla, O. Hanseth, V. Hespo, J. Ljungberg, E. Monteiro, and K. A. Simon (Eds.),. Oxford University Press, 2000, pp. 71-83.

[24]Miles, M. B. and Huberman, M. A. "Qualitative data analysis : an expanded sourcebook", 2. ed., Thousand Oaks, CA : Sage, cop. 1994

[25]Orlikowski "Using Technology and Constituting Structures: A Practice Lens for Studying Technology in Organizations," Organization Science, 11, 4, 2000, pp. 404428.

[26]Robey and Boudreau, M-C., "Accounting for the Contradictory Organizational Consequences of Information Technology: Theoretical Directions and Methodological Implications" Information Systems Research, Vol. 10, No. 2, June 1999, pp. 167-185

[27] Rogers, E. M. Diffusion of Innovations (4th ed.), Free Press, New York, 1990.

[28] Rönnbäck, L., Holmström, J., \& Hanseth, O. ”Exploring IT integration challenges: the Case of SCA Packaging.", Industrial Management and Data Systems,2007,pp..12761289.

[29]Westergren, U and Holmström, J. "Outsourcing as Open Innovation: Exploring Preconditions for the open Innovation Model in the Process Industry," The Proceedings of ICIS 2008 in Paris, France. 2008

[30] Yin, R. K., "Case study research : design and methods", 3 ed., Thousand Oaks : Sage Publications, cop. 2003

[31]Yoo, Y., K. Lyytinen, R.J. Boland. "Innovation in the Digital Era: Digitization and Four Classes of Innovation Networks". Working Paper, Temple University. 2008. 